\title{
"Não é assim de graça!": Lei de Cotas e o desafio da diferença
}

\author{
Maria Rosimére Salviano de Moura1; https://orcid.org/0000-0002-9316-0710 \\ Maria Ivonete Barbosa Tamboril'1; https://orcid.org/0000-0001-9891-9004
}

\begin{abstract}
Resumo
O estudo, de cunho qualitativo, investigou a experiência de escolarização vivenciada por um grupo de estudantes cotistas, de um Campus do Instituto Federal de Educação, Ciência e Tecnologia de Rondônia (IFRO), por meio de grupos focais. Os estudantes tratam as cotas como fruto de um direito, em função do processo de desigualdade social vivenciado historicamente pelos grupos aos quais pertencem e apontam a manutenção do princípio meritocrático nas cotas, a partir de uma perspectiva de atribuição do mérito, na qual as diferenças são consideradas. 0 critério étnico-racial das cotas, especificamente quanto ao estabelecimento de cotas para negros, revela que os discursos tensionados existentes na sociedade brasileira sobre a temática também se manifestam entre os estudantes. Defende-se que Psicologia tem muito a contribuir no processo de inserção de estudantes beneficiários de políticas de ações afirmativas, alicerçando seu trabalho na análise da dinâmica da inclusão/exclusão que se estabelece nas instituições.
\end{abstract}

Palavras-chave: Ação afirmativa; relações étnicas e raciais; grupos focais.

\section{"It is not free like that!!": Quota Act and challenges of difference}

\begin{abstract}
The qualitative study investigated the experience of schooling experienced by a group of quota students, from a Campus of the Federal Institute of Education, Science and Technology of Rondônia (IFRO), through focus groups. The students treat quotas as the result of a right, in function of the process of social inequality historically experienced by the groups to which they belong and point out the maintenance of the meritocratic principle in quotas, from a perspective of attribution of merit, in which the differences are considered. The ethnic-racial criterion of quotas, specifically regarding the establishment of quotas for blacks, reveals that the tensed discourses in Brazilian society on the subject also manifest among students. It is argued that Psychology has much to contribute in the process of insertion of students who are beneficiaries of affirmative action policies, grounding their work in analyzing the dynamics of inclusion / exclusion established in institutions.
\end{abstract}

Keywords: Affirmative action; ethnicand racial relations; focus groups.

\section{“¡No es así gratuitamente!”: Ley de Cuotas y el reto de la diferencia}

\section{Resumen}

El estudio, de cuño cualitativo, investigó la experiencia de escolarización vivenciada por un grupo de estudiantes cotizantes, de un Campus del Instituto Federal de Educación, Ciencia y Tecnología de Rondônia (IFRO), por intermedio de grupos focales. Los estudiantes tratan las cuotas como fruto de un derecho, en función del proceso de desigualdad social vivenciado históricamente por los grupos a los cuales pertenecen y apuntan la manutención del principio de merecimiento en las cuotas, a partir de una perspectiva de atribución del mérito, en la cual las diferencias son consideradas. El criterio étnico-racial de las cuotas, específicamente cuanto a lo establecimiento de cuotas para negros, revela que los discursos tensionados existentes en la sociedad brasileña sobre la temática también se manifiestan entre los estudiantes. Se defiende que Psicología tiene mucho a contribuir en el proceso de inserción de estudiantes beneficiarios de políticas de acciones afirmativas, respaldando su trabajo en el análisis de la dinámica de la inclusión/exclusión que se establece en las instituciones.

Palabras clave: Acción afirmativa; relaciones étnicas y raciales; grupos focales.

1 Universidade Federal de Rondônia. Porto Velho - RO - Brasil; rosisalviano@hotmail.com; ivonetetamboril@unir.br 


\section{Introdução}

A posição socioeconômica e o pertencimento étnico-racial são aspectos historicamente determinantes no Brasil ao acesso a condições efetivas de desenvolvimento das potencialidades do indivíduo e de possibilidades de participação social paritária entre os diversos grupos (Fraser, 2007). O combate à injustiça social, caracterizado pelo acesso a direitos fundamentais por todos, perpassa o reconhecimento da determinação de categorias sociais como raça, etnia, classe, gênero, dentre outras, na definição de posições sociais ocupadas pelos integrantes dos diferentes grupos.

Especificamente no acesso ao ensino superior público no Brasil tal quadro se revela sendo um privilégio de poucos. Lugar de excelência e meritocracia, pressupõeprocessos seletivos neutros, de distribuição natural de talentos, no entanto, os estudantes oriundos das escolas públicas, de famílias de camadas populares e negros, apesar de constituírem grupos majoritários da população brasileira, representam parcelas minoritárias no ensino superior.

Dessa forma, outras questões dificultam o acesso a condições de entrada destes estudantes no nível superior público, que não apenas o esforço individual empreendido, em um sistema de distribuição natural de talentos. Com a implantação da Lei no 12.711 (2012), conhecida como a Lei de Cotas, é regulamentada nacionalmente uma medida de ação afirmativa, por meio de reserva de vagas para estudantes de escolas públicas, pretos, pardos e indígenas em todo o sistema de educação superior e ensino técnico federal.

A criação desse marco legal está relacionada à mudança do entendimento sobre o processo de construção das desigualdades sociais e da produção de diferenças entre os diversos grupos sociais. O conceito de diferença é central para a formulação e desenvolvimento de medidas de ações afirmativas, visto que por meio de políticas de focalização há o reconhecimento da exclusão socioeconômica causadora de discriminação e vitimização de determinados grupos sociais, bem como há a busca do enfrentamento desse processo através do aumento da participação desses grupos no processo político, no acesso a bens materiais e direitos universais e de valorização das diferentes culturas.

Contudo, a ênfase na noção de diferença é um movimento pós-moderno. Candau (2008) ressalta que no processo histórico de tensão entre igualdade e diferença, na modernidade, a luta se dava pela busca da igualdade entre todos os seres humanos, já na pós-modernidade, houve um deslocamento de um polo ao outro, onde o tema da diferença toma notoriedade, busca-se a valorização da diferença, da identidade cultural. No entanto, a autora defende que a mudança de ênfase não deve levar a negação de nenhum dos polos de debate e sim a articulação desses.

Nessa mesma linha de análise histórica, Piovesan (2008) ressalta que a construção dos direitos humanos passou por uma primeira fase de proteção desses direitos marcada pela tônica da proteção geral, que expressava o temor da diferença, o indivíduo era concebido de forma genérica, geral e abstrata, no entanto, tal caracterização ne- gava a particularização de determinados grupos sociais que necessitavam de uma resposta específica e diferenciada para a proteção de seus direitos e atuação nas condições de vulnerabilidade. A virada da ênfase passa a valorizar a busca do direito a diferença, sem, contudo, negar o direito a igualdade. Nesse sentido, Santos (2003, p. 458) considera que é crucial: "... temos o direito a ser iguais quando a nossa diferença nos inferioriza; temos o direito a ser diferentes quando a nossa igualdade nos descaracteriza."

No entanto, o campo da diferença como base para o estabelecimento de medidas de garantia de direitos sociais encontra muitas resistências na sociedade brasileira. $\mathrm{O}$ interesse em desenvolver o estudo, que gerou este artigo, surgiu por meio da percepção de que a aprovação da Lei de Cotas produziu discursos tensionados, na maioria das vezes de teor favorável ou contrário à medida, estes, por vezes, contraditórios e polêmicos. Especificamente, o estudo buscou analisar o processo de escolarização dos estudantes cotistas de um Campus do Instituto Federal de Educação, Ciência e Tecnologia de Rondônia (IFRO).

Estudos sobre o impacto de um marco regulatório de tal dimensão é uma demanda de estudos emergente e urgente no campo da Psicologia, assim como em outras áreas do conhecimento. Em uma perspectiva social crítica, o ser humano é compreendido como histórico e social, se constituindo por meio da rede de inter-relações sociais que se estabelece em uma sociedade, produto e produtor da história e da cultura (Vigotski, 1935/2007). Assim, as relações sociais fornecem elementos para a constituição da identidade, o desenvolvimento de aptidões e aprendizagens e para a transformação social.

O modo como se constituem essas relações sociais e o reconhecimento da teia social que gera as desigualdades de oportunidades no acesso às instituições federais de ensino torna-seelemento fundamental para profissionais que pretendem atuar de forma crítica e consciente em contextos educacionais, bem como a produção de conhecimento sobre as formas como estão sendo vivenciados os processos de escolarização dos estudantes cotistas. Os funcionamentos institucionais podem contribuir para uma vivência ética da diversidade ou para a instrumentalização de relações reprodutoras de modos de agir e pensar que sustentem preconceitos e discriminações.

\section{Psicologia, ações afirmativas e relações étnico- raciais}

Os estudos no campo das ações afirmativas transitam entre as diversas áreas do conhecimento, constituindo-se em objeto de estudo interdisciplinar. As medidas de ações afirmativas têm a grande tarefa de contribuir no processo de democratização do acesso nas instituições federais de ensino, assim como na inclusão social dos diversos grupos que se encontram sub-representados em diferentes setores da sociedade. Uma tarefa dessa magnitude não pode se constituir em campo de atuação e estudo exclusivo de 
determinada disciplina, demandando a intersecção das diversas áreas do conhecimento para a promoção de uma efetiva inclusão educacional dos sujeitos beneficiados.

O levantamento dos estudos publicados nos periódicos de Psicologia revela as inúmeras possibilidades de aproximação da Psicologia com a temática, seja por meio de estudos teóricos focados na análise de discursos e representações sociais (Ferreira \& Mattos, 2007; Oliveira Filho, 2009; Guarnieri \& Melo-silva, 2010; Camino, Tavares, Torres, Álvaro,\& Garrido, 2014; Naiff, Naiff, \& Souza, 2009; Silva \& Silva, 2012), seja por estudos interventistas focadosnas relações sociais estabelecidas pelos integrantes das instituições e a construção de processos psicossociais como estereótipos, preconceitos e racismo (Nery \& Conceição, 2005; Nery \& Conceição, 2006; Nery \& Costa, 2009; Sousa, Bardagi, \& Nunes, 2013). Ainda, estudos focalizados nas instituições e suas ações para a promoção de inclusão dos diversos sujeitos de direitos, como os programas de permanência (Mayorga \& Souza, 2012; Jesus, 2013). O campo é vasto de possibilidades criadoras.

É possível perceber por meio desses estudos que dentre os critérios para o estabelecimento de medidas de ação afirmativa, especialmente a de cotas, o que produz maior tensionamento é o critério étnico-racial. As políticas de focalização expõem os indivíduos a processos afetivos que mobilizam tanto a politicidade quanto os preconceitos (Nery \& Conceição, 2006).

A Psicologia tem dado sua contribuição na produção de conhecimento sobre as relações étnico-raciais e para compreensão de fenômenos psicossociais ensejados pela temática. A categoria raça/etnia tem sido considerada nos estudos como elemento importante para a análise da produção e reprodução de desigualdades sociais.

Santos, Schucman e Martins (2012) identificam três períodos do pensamento psicológico brasileiro acerca das relações étnico-raciais, especificamente estudos sobre os negros. Caracterizam o primeiro período (final do século $X I X$ e o início do século $X X$ ) pelos estudos de Nina Rodrigues; estes, influenciados pelo darwinismo social, investigavam as características psicológicas dos negros e forneceram elementos para a configuração do negro como sujeito psicológico; o segundo período, de 1930 até 1950,é caracterizado pelos estudos de Virgínia Leone Bicudo, Aniela Ginsberg e Dante Moreira Leite, pela perspectiva culturalista e pelo debate da construção sociocultural das diferenças e da desconstrução do determinismo biológico das raças; o terceiro período é considerado de 1990 em diante, caracterizado como relacional e marcado pelos estudos sobre branqueamento e branquitude.

No campo da Psicologia Social os estudos de Iray Carone, Maria Aparecida Bento e Edith Pizza marcam a produção de conhecimento sobrebranquitude e branqueamento no Brasil (Carone \& Bento, 2012), com estudos que desvelam o conteúdo de identidade hegemônica, a branquitude, a identidade étnico-racial da pessoa branca é posta em foco. Dessa forma, esses estudos tomam a raça como uma construção social, revelando as relações de poder estabelecidas em fun- ção das diferenças étnico-raciais, evidenciando sua força na produção de discriminação e de hierarquização social.

Bento (2012) problematiza o campo das relações raciais ao evidenciar traços da identidade do branco brasileiro e o lugar de privilégio que ocupa, no qual ideologias racistas são fortemente construídas e reproduzidas para colocar o branco como referência de humanidade. Alerta que o silêncio e a cegueira em relação ao legado da escravidão para os brancos trazem benefícios simbólicos e materiais, “... permitem não prestar contas, não compensar, não indenizar os negros: no final das contas são interesses econômicos em jogo." (Bento, 2012, p. 27). E aponta que por essa razão as políticas de ações afirmativas são tão recusadas e taxadas de protecionistas na sociedade brasileira. Ainda, utiliza a noção de pactos narcísicos para caracterizar uma espécie de acordo, aliança ou pacto inconsciente e intergrupal existente na sociedade brasileira em relação ao racismo, em que há um silenciamento sobre tal e uma tendência a tratar as desigualdades raciais como um problema do negro (Bento, 2012).

Schucman (2012), ao investigar como sujeitos brancos se apropriam da categoria raça e do racismo na constituição de suas subjetividades, evidenciou que os ideais de raça e racismo, construídos no século XIX, ainda encontram ecos nos modos de subjetivação de indivíduos brancos, havendo a crença de que "ser branco" é determinante para formação nos indivíduos de características morais, intelectuais e estéticas. A autora defende que a Psicologia pode contribuir para a desconstrução do racismo na identidade branca ao demonstrar a suposta neutralidade que carrega e dos seus privilégios, assim como na elucidação de pactos narcísicos.

Assim, os estudos que abordam o contexto relacional em que são criadas as desigualdades raciais trazem uma concepção mais abrangente dos olhares acadêmicos lançados pela Psicologia Social que "... se deslocaram dos outros racializados para o centro sobre o qual foi construída a noção de raça, ou seja, para os brancos. Esse novo enfoque foi chamado de estudos sobre branquitude." (Santos \& cols., 2012, p. 172). Com isso, é feito um reconhecimento da importância política de se abordar a neutralidade racial do branco e da construção de subjetividade.

Se a temática das relações étnico-raciais, com focalização nas diversas nuances do processo de inserção nos negros na sociedade brasileira, tem um arcabouço teórico importante na Psicologia, não é possível dizer o mesmo em relação à temática indígena, apesar das análises sobre a branquitude também poderem ser aplicadas em relação aos indígenas, visto que o branco é estabelecido como modelo universal de humanidade de forma ainda mais contundente.

No entanto, esse cenário tem sofrido alterações, motivadas especialmente por ações do Sistema de ConseIhos de Psicologia em conjunto com entidades pela defesa dos direitos dos povos indígenas. Apesar do avanço, ainda é possível perceber o teor inicial dos encaminhamentos propostos. Vitale e Grubits (2009, p. 28), a partir de um estudo do tipo estado da arte, constatam a pouca inserção da Psicologia no estudo da temática indígena: “... a produção é ainda escassa e mais escassos são os autores que 
parecem desenvolver um trabalho, seja de pesquisa seja de intervenção, de forma contínua e consistente com os povos indígenas." Contudo, as autoras verificam um crescente esforço de debate e interlocução da Psicologia com a temática indígena e ressaltam uma perspectiva positiva sobre os trabalhos produzidos e as análises realizadas.

Assim, essa temática se estabelece como forte demanda para a produção de conhecimento e atuação profissional, bem como interpela o compromisso ético-político da profissão e de seus profissionais. Um dos grandes desafios que se estabelece nessa aproximação é a manutenção da garantia da autonomia dos povos indígenas, por meio da superação do “... Estado colonial presente, hegemônico nas nossas instituições; superar a ideologia colonial presente na nossa sociedade, nas relações entre os grupos sociais e entre as pessoas. E, finalmente, superar o que eu chamaria de subjetividade colonial presente nas próprias pessoas..." (Maldos, 2010, pp. 276-277).

A relação da Psicologia e de seus profissionais com a temática das relações étnico-raciais pressupõe uma virada epistemológica importante, na qual o foco dos estudos não deve ser dado de forma exclusiva à formação de subjetividades de negros e indígenas, mas especialmenteao desvelamento do processo de produção da subjetividade hegemônica, no caso brasileiro, a branca, dos privilégios simbólicos e materiais que usufrui e dos mecanismos sociais e institucionais que a preserva. A abordagem das relações étnico-raciais desta perspectiva permite a criação de novas possibilidades para o desenvolvimento de uma reflexão crítica sobre o processo de constituição destas relações no país e de desnaturalização do racismo.

\section{Método}

O estudo, de cunho qualitativo, investigou a experiência de escolarização vivenciada por um grupo de estudantes cotistas, de um Campus do Instituto Federal de Educação, Ciência e Tecnologia de Rondônia (IFRO), por meio de dois grupos focais. A pesquisa foi divulgada em todas as turmas da instituição em que havia ingresso de estudantes por cotas e o convite para participação foi feito de forma geral. Aqueles que manifestaram interesse em participar assinaram o Termo de Consentimento Livre e Esclarecido. A pesquisa foi aprovada pelo Comitê de Ética em Pesquisa da Universidade Federal de Rondônia.

No grupo 1 participaram oito estudantes, sendo cinco deles do curso de graduação e três dos cursos técnicos subsequentes ao ensino médio. No grupo 2 participaram nove estudantes, todos dos cursos técnicos integrados ao ensino médio. Nos grupos havia representação de todas as categorias de cotas, exceto indígenas em virtude de não existir acesso por cotas desses estudantes na instituição no período investigado. A separação por modalidade de ensino foi convencionada em função da diferença de idade e de escolarização entre os grupos, que poderia ser um fator de inibição entre os estudantes do ensino técnico integrado ao médio.
Para Gatti (2012, p. 11) o grupo focal constitui-se em "... uma técnica importante para o conhecimento das representações, percepções, crenças, hábitos, valores, restrições, preconceitos, linguagens e simbologias prevalentes no trato de uma dada questão...”. O contexto de interação estabelecido deve propiciar a captação de significados, menos individualizados, por meio de um diálogo aberto que permita a expressão de ideias e de processos emocionais vivenciados.

Nos grupos existiram muitos momentos de consensos, tornando possível a captação de ideias que representavam o grupo, contudo existiram momentos de discordâncias, com discursos tensionados, que possibilitou a identificação da dinâmica presente no estabelecimento das argumentações, as mudanças de posicionamento ou a abertura para novas nuances de uma concepção anteriormente defendida.

Os dados foram analisados a partir da perspectiva da Análise de Conteúdo de Bardin (1977/2013) e sistematizados em quatro categorias temáticas, sendo elas:A condição de estudante oriundo de escola pública: um lugar que diferencia; Negros: as tensões e a autoidentificação de cor/raça; As relações interpessoais; A condição de estudante cotista: um direito a ter direitos.

\section{Resultados e Discussões}

\section{A condição de estudante oriundo de escola pública: um lugar que diferencia}

A condição de estudante oriundo de escola pública surge como o fator de maior impacto no processo de escolarização dos estudantes, é a que encontra maior consenso entre eles como critério para reserva de vagas. Afirmam que a maior barreira vivenciada é em relação aos conhecimentos prévios, necessários para o acompanhamento dos cursos, e que essa situação os diferenciam da maioria dos estudantes oriundos de escolas privadas e daqueles que tiveram melhores oportunidades de aprendizagem na rede pública. Especialmente, são colocadas dificuldades em relação às disciplinas das áreas de exatas, disciplinas estas que compõem, de forma bastante intensa, os currículos dos cursos que frequentam.

Quanto ao desempenho acadêmico dos estudantes cotistas, os relatos demonstram processos bastante diferenciados, há estudantes que dizem terem vivenciado muitas dificuldades no processo de aprendizagem e que isto fez com que o seu desempenho tenha sido prejudicado e há outros que relatam que apesar das dificuldades o desempenho acadêmico não foi afetado. No Grupo 2, afirmam de forma unânime que as dificuldades são iniciais, tratando-as como uma fase de adaptação, passando esta fase o processo de aprendizagem torna-se menos conturbado possibilitando um melhor desempenho e não sendo percebidas diferenças significativas em relação aos demais estudantes. 
Marcos ${ }^{1}-$ Grupo 2: ...tem matérias que nós nunca vimos e que outros alunos, digamos assim, de escolas privadas já tinham visto, já tinham conhecimento e aí você fica "nossa isso existia, o que é que eu vou fazer agora?!" Tipo assim, é correr para aprender.

Os estudantes informam que essa situação inicial os coloca numa condição de bastante vulnerabilidade, dificultando uma adequada evolução nos cursos, cujas consequências podem ser reprovações ou evasões. Apontam, também, como elemento importante para superação dessas dificuldades, as redes de apoio que estabelecem com os demais estudantes, por meio da formação de grupos de estudos e do apoio dado por muitos docentes através de encontros individualizados e retornos constantes a conteúdos que compõem os currículos dos anos anteriores durante as aulas.

A partir dos relatos de estudantes negros e de classes populares participantes do Programa Conexões de Saberes da Universidade Federal de Minas Gerais, Mayorga e Souza (2012) verificam que uma trajetória bem-sucedida na universidade depende de uma série de estratégias individuais e coletivas de superação de desigualdades, entre elas a constituição de redes de apoio, em que as experiências e estratégias de superação de barreiras são compartilhadas e coletivizadas pelos estudantes.

\section{Negros: as tensões e a autoidentificação de cor/raça}

Há, por parte dos estudantes, uma leitura histórica importante do processo de inserção de negros e indígenas na sociedade brasileira e das desigualdades sociais vivenciadas por estes grupos sociais, entretanto, esta compreensão não gera em todos os participantes o reconhecimento da necessidade das cotas com base no critério étnico-racial, especificamente quanto ao estabelecimento de cotas para negros, havendo uma maior aceitação da aplicação deste critério no caso de reserva de vagas para indígenas.

Esse movimento de contraposição às cotas para negros, apesar de ser uma posição da minoria dos estudantes participantes nos dois grupos focais realizados, trouxe uma dinâmica importante ao Grupo 2, onde os discursos foram mais acirrados e revelaram as tensões existentes quanto à questão:

\section{Trecho Grupo 2}

Jane: Eu e o Felipe, nós temos um ponto de vista um pouco diferente. Você assumir uma cota para negro é você assumir ser preconceituoso...

Jéssica: Eu também acho.

1 Os nomes dos estudantes são fictícios e foram escolhidos por eles.
Jane: Porque você acha que um negro não tem a capacidade de um branco?!

Ana: Eu também penso isso.

Felipe: Eu concordo com a de renda, porque daí muitas pessoas...

Jane: De renda eu concordo.

Felipe: Não tem condições de conseguir estudar e tudo mais, comprar material...

Jane: Ter acesso a uma boa educação.

Felipe: Agora, racial eu acho completamente inútil.

Marcos: Mas essa cota relacionada ao negro não é aquela dívida com os escravos, antepassados!?

Felipe: É tipo assim, uma pessoa está recebendo uma ajuda por causa dos seus antepassados é completamente sem noção.

Karla: Mas, a nossa sociedade julga a gente.

Felipe: Aqui no colégio não julga.

Pesquisadora: Nossa sociedade o quê?

Karla: Ela julga a gente só pela cor, você vai num lugar, num lugar chique, a pessoa olha para você porque você é negra, já te encara, não te atende bem, então é uma ajuda para a gente negra. Eu mesmo sofro direto isso, só que eu levanto a cabeça e vou. Eu falo "gente eu estou lá, igual a qualquer outra pessoa, eu passei, eu fiz a prova”, não quer dizer que eu sou inferior aos outros, mas, isso existe muito...

A negação do efeito do pertencimento étnico-racial é feita pelo uso do argumento de melhoria da qualidade da escola pública como medida mais adequada e da defesa de que as questões econômicas e sociais são mais impactantes do que o fato de ser negro. Esse posicionamento revela, ainda que de forma contraditória, visto que são estudantes cotistas, a apropriação dos discursos de um estado de democracia racial, ainda proferidos na sociedade brasileira, em que o processo de implantação de medidas de cotas étnico-raciais acirrou tais discursos.

As tensões presentes em função do critério racial das cotas também são evidenciadas no estudo de Assis (2014, p. 333) que para os participantes da pesquisa “... o imperativo da "raça" não é concebido como um instrumento que provoca desigualdades sociais, isto é, para maioria desses alunos a desigualdade no seu caráter racial não é protagonista dos problemas sociais." O argumento de melhoria da qualidade das escolas públicas como mecanismo mais eficaz para resolução das desigualdades sociais também é 
encontrado nos resultados dos estudos de Ferreira e Mattos (2007), Oliveira Filho (2009), Guarnieri e Melo-Silva (2010), Camino \& cols.(2014), Naiff, Naiff, e Souza (2009), Assis (2014).

A ideologia do estado de democracia racial estabelecido no Brasil mobiliza a produção de discursos e a forma de compreensão da produção de desigualdades raciais, de tal forma que as próprias vítimas são influenciadas em relação ao desenvolvimento de concepções que negam a existência e importância do racismo na produção das desigualdades que os afetam e de um posicionamento político favorável às medidas reparatórias.

Ainda, o processo de autoidentificação de cor/raça de boa parte dos estudantes participantes deste estudo é permeado por aspectos bastante complexos. No grupo 2, alguns estudantes relatam ter dificuldade neste processo, em função da miscigenação presente em suas famílias. Essa complexidade no processo de autoidentificação de cor/raça também é fortemente evidenciada no Grupo 1. Neste grupo, seis entre os oito estudantes participantes se declararam pardos e ingressaram na instituição por meio da reserva de vagas por critério étnico-racial; no entanto, quando se levantam questões sobre este critério, a maioria dos estudantes demonstra certo distanciamento da questão, como se falassem de outros e não deles, revelando uma postura ambígua sobre a temática.

Silva e Leão (2012) abordam que a identidade parda é um elemento central no estudo das relações étnico-raciais e que a multiplicidade de significados que ela pode assumir ainda precisa ser explorada por estudos mais específicos. As autoras concebem a identificação racial e a mensuração da discriminação como centrais das relações raciais brasileiras, visto que apesar das possibilidades de conciliação identitária e o compartilhamento de situações socioeconômicas parecidas por pretos e pardos, sendo a junção dos mesmos em um único grupo importante para destacar tal realidade, estão longe de se constituírem um grupo homogêneo nos processos discriminatórios que vivenciam e automaticamente na concepção sobre a realidade étnico-racial brasileira. Essas são questões que podem permear a postura dos estudantes cotistas quanto à temática étnico-racial.

Outro ponto referente à autoidentificação étnico-racial abordada e discutida pelos estudantes são as dificuldades das pessoas heteroclassificadas de cor preta se identificar com a cor, muitas vezes, se declarando pardos, enfatizam como a construção histórica da imagem do negro impede e/ou dificulta o processo de identificação positiva com a negritude.

Schucman (2012, p. 109) em estudo com sujeitos brancos identifica a concepção de superioridade moral, intelectual e estética presente na subjetividade branca, que caracteriza a construção social da branquitude, produzindo “... significados compartilhados, dos quais os sujeitos se apropriam, singularizam, produzem sentidos e atuam sobre eles, de alguma forma, reproduzindo-os." Reversamente, uma série de características negativas é atribuída aos demais grupos sociais. No caso dos negros, ainda muito cedo, conforme relato acima, se entra em contato com uma gama de referências identitárias de baixo status e valor.

A identidade dos indivíduos é desenvolvida a partir da articulação aos valores socialmente associados a seu grupo de pertencimento, numa relação dialética entre o indivíduo e a sociedade como um todo (Vigotski,1935/2007), se há uma forte construção social de valoração negativa ao grupo social, a construção positiva da identificação com este grupo se torna prejudicada.

Além disso, os estereótipos e preconceitos, em que estão imbricadas questões sociais e individuais, geram impedimentos à ampliação da consciência social, pois não permitem a compreensão da construção sociocultural das diferenças e das desigualdades, afetando inclusive o posicionamento político das próprias vítimas desta trama social, como no caso dos estudantes cotistas que se manifestam contrários a uma política que os beneficiou.

\section{As relações interpessoais}

Quanto aos aspectos interacionais estabelecidos entre os estudantes cotistas e a comunidade acadêmica, os participantes revelam que o fato de serem cotistasnão é algo que sobressai no estabelecimento das relações interpessoais, especialmentenas relações com os demais estudantes, não existindo processos discriminatórios.

O fato de os cursos da instituição ainda não terem estabelecido altos índices de concorrência, em que as disputas não são tão acirradas, pode ser um aspecto que contribua para o estabelecimento de um ambiente interacional mais favorável à inserção dos estudantes cotistas. Outro aspecto refere-se à articulação de critérios sociais (origem de escola pública e renda per capita) com o critério racialpromovido pela Lei de Cotas que pode ter gerado uma maior aceitação dessa medida, visto que, em estudos anteriores os processos interacionais são identificados de forma mais tensionada.

Sousa, Bardagi e Nunes (2013) identificaram escores mais baixos, na dimensão interpessoal, em testes realizados com estudantes cotistas, caracterizando dificuldades, no âmbito social, que podem ser decorrentes do preconceito e da desconfiança que o sistema de cotas enfrenta no Brasil. Em estudos com intervenções psicodramáticas, (Nery \& Conceição, 2005, 2006; Nery \& Costa, 2009) foram encontrados fortes elementos ideológicos contrários às cotas raciais que permeiam os processos interacionais e afetivos entre os estudantes cotistas e não-cotistas. Assis (2014) identificou processos de diferenciação entre estudantes cotistas e não-cotistas em um ambiente acadêmico, sendo os espaços de integração utilizados como instrumentos para inclusão ou exclusão de colegas, contudo esse mecanismo de segregação acontecia de forma sutil, dificultando afirmações sobre processos de discriminação.

Formas veladas ou não de discriminação geralmente permeiam os processos de interação estabelecidos em relação aos estudantes cotistas, contudo nesse estudo não foi relatada a vivência de tais manifestações. Com isso não se 
nega a reconhecimento da existência de discursos tensionados, especialmente em relação ao critério racial das cotas.

No entanto, a partir dos dados e, em uma posição otimista, seria possível pensar que tais questões tenham se diluído frente às inúmeras possibilidades de interações que o contato humano permite, de maneira que a forma de ingresso na instituição não seja um determinante maior nestas interações? Nesse aspecto, assim como Schucman (2012) pautada nas contribuições de Vigotski (1926/1999) afirmamos que se por meio das relações sociais, o ser humano é constituído, forma sua identidade, afetos, valores, torna-se racista, preconceituoso, opressor, também é por meio destas mesmas mediações que são possíveis movimentos antagônicos de promoção da alteridade e de desidentificação.

\section{A condição de estudante cotista: um direito a ter direitos}

A condição de estudante cotista é algo que consideram que os diferencia no acesso, colocando-os numa posição mais equitativa e referem-se a tal condição como fruto de um direito, em função do processo de desigualdade vivenciado pelos grupos sociais aos quais pertencem e de forma unânime, por serem oriundos de escolas públicas. $O$ critério étnico-racial das cotas, conforme abordado anteriormente, não se constituiu um elemento de consenso entre os estudantes.

A questão do mérito surge como fator importante de análise e do reconhecimento das cotas como um direito. Há uma constatação de que o princípio da meritocracia se mantém, pois os grupos continuariam a concorrer por vagas, no entanto sob um novo contexto, a partir de condições prévias mais próximas ou igualitárias:

Sofia - Grupo 1: ...a concorrência vai continuar, são quarenta vagas, vinte para as cotas e mais vinte vagas, a concorrência de quem teve uma educação melhor vai continuar, só que eles vão disputar mais entre eles mesmos e aí abre a porta para quem não teve uma educação boa, para que também tenham a oportunidade de entrar e nós também vamos ter que brigar pela nossa vaga entre nós mesmos, não é assim de graça! ${ }^{2}$

Tais concepções estão em consonância com o que, segundo Medeiros (2007, p. 128), os proponentes da ação afirmativa defendem "... não é o abandono do mérito como critério de admissão, mas a reelaboração desse critério de modo a torná-lo, não somente, mais justo, mas também mais eficaz como instrumento de avaliação." Assim, outros fatores são levados em consideração nos processos de seleção, juntamente com a capacidade de superar obstáculos.

Apesar das reiteradas falas de que não vivem processos de discriminação e preconceito na instituição os estudantes demonstram que há uma necessidade de reflexão

2 Trecho de fala utilizado no título deste trabalho. e ampliação de informações que possam contrapor os repertórios discursivos contrários e contraditórios presentes nos discursos da maioria das pessoas em relação ao sistema de cotas e às questões sociais, étnico-raciais e ideológicas que suscita:

Henrique - Grupo 2: A sugestão é a que todo mundo já deu, a princípio exteriorizar essa conversa, promover o debate, porque se você exterioriza isso, daqui você vai ajudar as outras pessoas também a compreenderem melhor, a ter uma visão diferente em relação a isso. Há pouca... embora a sociedade debate muito sobre esse assunto com inúmeras críticas, mas há pouca discussão aprofundada sobre o assunto, onde você tem uma visão melhor, a maioria das discussões são mais baseadas em estereótipos de alguém que não concorda e vamos discutir em função daquela pessoa que não concorda.

Tal chamado remete à necessidade da construção de espaços de mediação produtores de desconstruções nos discursos hegemônicos, em relação aos cotistas e ao processo de produção de desigualdades sociais, especialmente à necessidade de contraposição dos ideais de branquitude que impedem o reconhecimento do demarcador racial como determinante essencial na produção de desigualdades sociais. Espaços que permitam a reinvenção de concepções sobre a sociedade, o ser humano e as diferenças, a partir da potencialidade do desenvolvimento humano mediado pelas intersubjetividades (Vigotski, 1926/1999).

\section{Considerações Finais}

O estudo com os estudantes cotistas oportunizou conhecer aspectos da experiência de inserção por cotas na instituição a partir do ponto de vista destes. O grupo focal como instrumento de coleta de dados mostrou-se profícuo na discussão de uma temática tão complexa, carregada de estereótipos e polêmicas, assim como possibilitou não apenas o acesso a informações sobre o objeto de estudo, mas um processo de amadurecimento sobre essa experiência por parte dos estudantes participantes. O compartilhamento de ideias e experiências, assim como as divergências surgidas, mostraram-se importantes para a apropriação mais consciente dessa experiência.

Esse processo manifesta-sea partir da solicitação de externalização da discussão sobre a temática para outros espaços, os estudantes atentam para a necessidade de reflexão e ampliação de informações de forma mais aprofundada, que possam contrapor os repertórios discursivos contrários e contraditórios presentes nos discursos sobre o sistema de cotas e às questões sociais, étnico-raciais e ideológicas que suscita.

A construção de espaços de mediação produtores de desconstruções nos discursos hegemônicos em relação aos cotistas e ao processo de produção de desigualdades sociais, bem como, a análise da dinâmica da inclusão/exclusão 
estabelecidas nas instituiçõesé um importante campo para atuação dos psicólogos educacionais e para produção de conhecimento pela Psicologia.

\section{Referências}

Assis, Y. S. (2014). Relações sociais e sentidos de justiça social após a adoção da política de cotas na Universidade Federal de Sergipe. Tomo, (24), 297-334.

Bento, M. A. S. (2012). Branqueamento e branquitude no Brasil. In: Carone, I.; Bento, M. A. S. (Orgs.), Psicologia Social do Racismo (pp. 25-58). Petrópolis: Vozes.

Bardin, L. (2013). Análise de conteúdo (Reto, L.\& Pinheiro, A.,Trad.). São Paulo: Livraria Martins Fontes.(Trabalho original publicado em 1977).

Candau, V. M. (2008). Direitos Humanos, educação e interculturalidade: as tensões entre igualdade e diferença. Revista Brasileira de Educação, 13 (37), 45-57.

Carone, I.; Bento, M. A. S. (Orgs.). (2012). Psicologia Social do Racismo. Petrópolis: Vozes.

Camino, L.; Tavares T. L.; Torres, A. R. R.; Álvaro, J. L.; Garrido. A. (2014). Repertórios discursivos de estudantes universitários sobre cotas raciais nas universidades públicas brasileiras. Psicologia e Sociedade, 26(spe.),117-128.

Ferreira, R. F.; Mattos, R. M. (2007). O afro-brasileiro e o debate sobre o sistema de cotas: um enfoque psicossocial. Psicologia Ciência e Profissão, 27(1), 46-63.

Fraser, N. (2007). Reconhecimento sem ética? Lua Nova, 70,101138.

Gatti, B. A. (2012). Grupo focal na pesquisa em ciências sociais e humanas. Brasília: Líber Livro.

Guarnieri, F. V.; Melo-silva, L. L. (2010). Perspectivas de estudantes em situação de vestibular sobre as cotas universitárias. Psicologia e Sociedade, 22(3), 486-498.

Jesus, J. G. O. (2013). Desafio da convivência: assessoria de diversidade e apoio aos cotistas (2004-2008). Psicologia Ciência e Profissão, 33(1), 222-233.

Lei n. 12.711, de 29 de agosto de 2012 (2012). Dispõe sobre o ingresso nas universidades federais e nas instituições federais de ensino técnico de nível médio e dá outras providências. Brasília. 2012. Recuperado: 10 nov. 2018. Disponível: http://www.planalto. gov.br/ccivil_03/_ato2011-2014/2012/lei/l12711.htm

Maldos, P. R. M. (2010). A contribuição indígena na construção do nosso futuro comum. In: Conselho Regional de Psicologia $6^{\circ}$
Região (Org.), Psicologia e Povos Indígenas (pp. 272-277). São Paulo: CRPSP.

Mayorga, C.; Souza, L. M. (2012). Ação afirmativa na universidade: a permanência em foco. Revista Psicologia Política, 12(24), 263281.

Medeiros, C.A. (2007). Ação afirmativa no Brasil: um debate em curso. In: Santos, S.A. (Org.), Ações afirmativas e combate ao racismo nas Américas (pp. 121-140). Brasília: Ministério da Educação: Unesco.

Naiff, D. G. M.; Naiff, L. A. M.; Souza, M. A. (2009). As representações sociais de estudantes universitários a respeito das cotas para negros e pardos nas universidades públicas brasileiras. Estudos e Pesquisa em Psicologia, 9(1), 219-232.

Nery, M. P.; Conceicao, M. I. G. (2005). Sociodrama e política de cotas para negros: um método de intervenção psicológica em temas sociais. Psicologia Ciência e Profissão, 2(1), 132-145.

Nery, M. P.; Conceicao, M. I. G. (2006). Política racial afirmativa e afetividade na interação intergrupal. Interação em Psicologia, 10(2), 362-374.

Nery, M. P.; Costa, L. F. (2009). Afetividade entre estudantes e sistema de cotas para negros. Paidéia,19(43), 257-266.

Oliveira Filho, P. (2009). A mobilização do discurso da democracia racial no combate às cotas para afrodescendentes. Estudos de Psicologia, 26(4), 429-436.

Piovesan, F. (2008). Ações afirmativas no Brasil: desafios e perspectivas. Revista Estudos Feministas, 16(3), 887-896.

Santos, B. S. (2003). Por uma concepção multicultural dos direitos humanos. In: Santos, B. S. (Org.), Reconhecer para libertar: os caminhos do cosmopolitismo multicultural (pp.427-461). Rio de Janeiro: Civilização Brasileira.

Santos, A. O.; Schucman, L. V.; Martins, H. V. (2012). Breve histórico do pensamento psicológico brasileiro sobre relações étnicoraciais. Psicologia Ciência e Profissão, 32(spe),166-175.

Schucman, L. V. (2012). Entre o "encardido", o "branco" e o "branquíssimo": Raça, hierarquia, e poder na construção da branquitude paulistana. Tese de Doutorado, Instituto de Psicologia da Universidade de São Paulo, São Paulo-SP.

Silva, G. M.; Leão, L. T. S. (2012). O paradoxo da mistura: Identidades, desigualdades e percepção de discriminação entre brasileiros pardos. Revista Brasileira de Ciências Sociais, 27(80), 117-133.

Silva, P. B.; Silva, P. (2012). Representações sociais de estudantesuniversitários sobre cotas na universidade. Fractal Revista de Psicologia, 24(3), 525-542. 
Sousa, H.; Bardagi, M. P.; Nunes, C. H. S. S. (2013). Autoeficácia na formação superior e vivências de universitários cotistas e não cotistas. Avaliação Psicológica, 12(2), 253-261.

Vigotski, L. S. (1999). Teoria e método em psicologia. São Paulo: Martins Fontes, (Trabalho original publicado em 1926).
Vigotski, L. S. (2007). A formação social da mente. São Paulo: Martins Fontes. (Trabalho original publicado em 1935).

Vitale, M. P.; Grubits, S. (2009). Psicologia e Povos Indígenas: um estudo preliminar do "Estado da Arte". Revista Psicologia e Saúde, $1(1), 15-30$.

Este artigo é derivado da dissertação de mestrado intitulada "Não é assim de graça!: Lei de Cotas e o desafio da diferença" sob a orientação da Profa. Dra. Maria Ivonete Barbosa Tamboril.

As autoras agradecem ao Instituto Federal de Educação, Ciência e Tecnologia de Rondônia/Campus Porto Velho Calama por seu apoio financeiro. unrestricted use, distribution and reproduction in any medium, provided the original article is properly cited. 